\title{
An Innovative Method for the Control of Legionella Infections in the Hospital Hot Water Systems with a Stabilized Hydrogen Peroxide-Silver Formulation
}

\author{
Hillel Shuval ${ }^{1,2}$, Rachel Yarom ${ }^{3}$, Rivka Shenman ${ }^{3}$ \\ ${ }^{1}$ Department of Environmental Health Sciences, Hadassah Academic College, Jerusalem, Israel \\ ${ }^{2}$ Hebrew University of Jerusalem, Israel \\ ${ }^{3}$ Public Health Laboratory, Ministry of Health, Haifa, Israel
}

10.3396/ijic.V5i1.006.09

\begin{abstract}
Legionella pneumophila contamination of hot water systems are particularly difficult to control due to the optimal growth conditions, protection by biofilms and the fact that chlorine and many other disinfectants are less effective at high temperatures. This paper reports on a 24 month study using an innovative method to control Legionella pneumophila in the closed loop hot water system of a major hospital in Israel which has suffered a serious out-break of Legionaires disease in their BMT unit. They had failed to control the Legionella infections by the conventional use of repeated shock treatments with chlorine up to $2000 \mathrm{ppm}$ and by raising the water temperature to $70^{\circ} \mathrm{C}$. During the period between October 2005 and September 2007 an innovative disinfectant process, based on a patented, stabilized, non-toxic, taste free, bactericidal/bacteriostatic, heat resistant formulation of hydrogen peroxide containing a minute amount of oligodynamic silver was used to effectively disinfect the hot water system and achieve total long term control of Legionella pneumophila. The combined formulation of $\mathrm{H}_{2} \mathrm{O}_{2}$ and silver and other metals is some 100 times more powerful as a disinfectant than hydrogen peroxide alone and can provide a long lasting effective disinfectant residual. Our studies show that the formulation's disinfection power increases significantly as water temperature increases which contributes to its effective control of Legionalla bacteria in hot water systems which normally operate at temperatures up to $40-50^{\circ} \mathrm{C}$. The silver ion deposit on the pipe walls have a bacteriostatic effect. At the end of the 24 month test period it can be stated that the stabilized $\mathrm{H}_{2} \mathrm{O}_{2}$-silver formulation effectively controlled Legionella pneumophila in the hospital ward's hot water system for the first time after years of chronic problems and has proved to be a promising and economical option for the long term control of Legionella bacteria in closed loop hot water systems.
\end{abstract}

Key words

Legionnaires disease; control; hot water systems; hydrogen peroxide; silver; disinfection; Israel

\section{Corresponding author}

Hillel Shuval, Director, Department of Environmental Health Sciences, Hadassah Academic College, Jerusalem, Israel, Email: hshuval@vms.huji.ac.il 


\section{Introduction}

Legionella pneumophila contamination of hot water systems are particularly difficult to control due to fact that hot water systems, which usually operate at 40$50^{\circ} \mathrm{C}$ provide the optimal growth conditions for Legionella. Another factor is that deposits of water hardness, calcium and magnesium, build up particularly in hot water systems, and provide rough pocked surfaces and conditions for biofilms development which result in favourable conditions for the protection of bacterial infections from chemical disinfection processes. A third factor is that chlorine and some other disinfectants, which have conventionally been used, are less effective at the high temperatures typical of hot water systems. The literature reports on repeated re-infections, frequent difficulties, and problems in controlling Legionella infections in general and particularly in hot water systems. ${ }^{1}$

Several Legionnaires disease outbreaks have occurred in hospitals and hotels in Israel and a survey by the Ministry of Health detected Legionella bacteria in the hot water systems in 10 out of 12 hospitals in various parts of the country. ${ }^{2}$ Despite efforts to control the Legionella infections few have been effective for long periods. This paper reports on a 24 month pilot study using an innovative method to control Legionella pneumophila in the closed loop hot water system of Rambam Hospital- a major hospital in the north of Israel, which has suffered a serious nosocomial outbreak of Legionnaires' disease in its Bone Marrow Transplantation- BMT unit- one of the most sensitive units in the hospital. ${ }^{3}$

The hospital had failed to achieve adequate control by the conventional use of repeated shock treatments with chlorine up to $2000 \mathrm{ppm}$ or by raising the water temperature to $70^{\circ} \mathrm{C}$. These procedures achieved only limited control for a few weeks or months only. Constant operation of the hot water system at $50^{\circ} \mathrm{C}$, which is a temperature which can inactive the Legionella bacteria, was not adopted due to the danger of scalding.

Our studies have shown that Legionella strains are ubiquitous in most natural water sources in Israel and that irrigation-aerosol exposed agricultural workers carry a significant excess of Legionella pneumophilia anti-bodies over controls. ${ }^{4}$ Thus, the known or reported outbreaks of the disease may be the tip of the iceberg indicating that there is a need to introduce effective methods of Legionella control in hospitals, hotels and public institutions.

\section{Methods}

During the course of the period between October 2005 and September 2007 an innovative disinfection process using a patented, stabilized, non-toxic, taste free, bactericidal/ bacteriostatic, heat resistant formulation of hydrogen peroxide containing a minute amount of oligodynamic silver was used to effectively disinfect the hot water system and achieve total control of Legionella pneumophila.

Based on the approval of the Ministry of Health, the following disinfection regime was introduced in the closed loop hot water system of the hospital's 50 bed BMT ward. The control treatment included two stages: A first stage, initial shock dose of the formulation which provided a 500 ppm concentration of $\mathrm{H}_{2} \mathrm{O}_{2}$. After a few hours this initial shock dose was totally flushed out of the system. Shower heads, hot water faucets and other end-of-the-line plumbing fixtures were disinfected in $4 \% \mathrm{H}_{2} \mathrm{O}_{2}$ solutions of the formulation. There were no residual odour or taste problems as occur when high doses of chlorine are used. The second stage included automatic continuous feeding, monitoring and control of the formulation into the ward's closed hot water system at a dose of $20 \mathrm{ppm}$ of $\mathrm{H}_{2} \mathrm{O}_{2}$ and a minute concentration of silver for a few hours each day. The concentration of disinfectant was monitored and controlled continuously by a specially designed automatic system. At the request of the hospital the control procedure was also introduced in the Oncology Department where positive tests for Legionella had been revealed.

\section{Laboratory test methods for Legionella}

Water samples drawn in $500 \mathrm{ml}$ sterile containers, with $0.5 \mathrm{ml}$ thiosulfate, were tested for Legionella species at monthly intervals in the hospital's laboratory or assayed in the Ministry of Health Public Health Laboratory in Haifa, using officially approved methods for Legionella testing. Water samples were concentrated by filtration and inoculated on buffered charcoal yeast extract (BCYE) plates. Plates were examined daily for growth. 
Suspected colonies, were sub-cultured on to fresh BCYE agar and confirmed as Legionella species by species-specific anti-sera. ${ }^{5,6}$

\section{Results}

Prior to the initiation of the control program Legionella species were frequently detected in water samples drawn from various sites in the hospital in concentrations ranging form 20 to $1400 \mathrm{cfu} / 100 \mathrm{ml}$. The hospital initiated various control programs including superheating the hot water tanks to $70^{\circ} \mathrm{C}$ and shock treatment with chlorine doses up to $2000 \mathrm{ppm}$. With these procedures Legionella species were eliminated temporarily and re-emerged in low concentration up to $20 \mathrm{cfu} / 100 \mathrm{ml} .^{3}$

During the 24 month study period all of the monthly tests for Legionella bacteria in the hot water system of both departments were negative except for one single positive sample detected after 10 months at a dead end pipe which was then corrected and put into the closed loop flow. As a precaution, a limited scale, shock treatment cycle was repeated in the infected area only. At the end of the 24 month test period it can be stated that the stabilized $\mathrm{H}_{2} \mathrm{O}_{2}$-silver formulation effectively controlled Legionella pneumophila in both of the hospital ward's hot water systems for the first time after years of chronic problems.

\section{Discussion}

\section{Evaluation of Alternative Legionella Disinfectants}

There are many problems in achieving effective disinfection of hot water systems to control Legionella. Few of the conventional disinfectants have been shown to have long term efficacy, particularly in hot water systems which serve as one of the main foci of Legionella multiplication and dissemination. The optimum amplification range of Legionella is a narrow band of $30^{\circ} \mathrm{C}$ to $40^{\circ} \mathrm{C}$. Above $45^{\circ} \mathrm{C}$ Legionella is killed with time and at $50^{\circ} \mathrm{C}$ it may take up to two hours to attain a $90 \%$ kill, while at $70^{\circ} \mathrm{C}$ a $100 \%$ kill is rapid. However, it must be pointed out that at temperatures above $45-50^{\circ} \mathrm{C}$ in the hot water supply system used by consumers, such as in hospitals or hotels there is a serious danger of scalding. There is also a problem of pipe corrosion and energy costs are high. Thus this method has serious constraints. The Association of Water Technologies ${ }^{1}$ has published an evaluation of the alternative Legionella disinfection technologies, summarized in brief in Table I.

Tests have shown that the specific formulation is effective in inactivating Legionella at the concentrations recommended for use in this study. Our studies at HU have shown that the combined formulation of $\mathrm{H}_{2} \mathrm{O}_{2}$ and silver and other metals is some 100 times more powerful as a disinfectant than hydrogen peroxide alone and can provide a long lasting effective disinfectant residual of many days and weeks. ${ }^{7}$ Our research has revealed that the potentiating action of the two chemicals working in combination is basically the result of a two stage biological effect on the bacterial cell wall rather than the result of the formation of some new more potent chemical form as had been previously hypothesized. ${ }^{8}$

While the disinfection ability of chlorine is seriously reduced in hot water systems, our investigations have shown that the $\mathrm{H}_{2} \mathrm{O}_{2}$-silver formulation is heat stable to high temperatures and its disinfection power increases significantly as water temperature increases. At water temperatures of $38^{\circ} \mathrm{C}$ there is an increased rate of bacterial inactivation by a factor of well over 100 than that achieved at $18^{\circ} \mathrm{C} .{ }^{9}$ This is an important feature of the formulation which contributes to its effective control of Legionella bacteria in hot water systems which normally operate at temperatures up to $40-50^{\circ} \mathrm{C}$. Our studies also have indicated that the long term efficacy of the disinfectant is partially due to the bacteriostatic effect of the small amounts of silver which deposit on the walls of the piping system or tanks, and coat sediments and biofilms. We have hypothesized that the positive metal ions bond to the negative bacterial cell walls sites, disrupting membrane structure which leads to bacterial cellular death aided by $\mathrm{H}_{2} \mathrm{O}_{2}$ penetration.

Recent research reports have revealed that silver ions are effectively used in several medical applications which take advantage of the nanoscale silver particles which have so much surface area that small concentrations are effective antiseptics. It has been reported that the surface binding performance of the silver particles blocks the formation of a thick carpet of bacterial biofilm and is a key to avoiding infections. ${ }^{10}$ 


\section{Table I: Evaluation of Alternative Legionella Disinfection Technologies ${ }^{1}$}

\section{Heat-and-flush (heat shock)}

Raising the hot water tank temperature to $60-70^{\circ} \mathrm{C}$ - Thermal eradication provides only temporary results: it is very labour intensive, presents scalding risks, has associated high energy costs and corrosion problems, is difficult to achieve complete effectiveness and at best provides only short term (weeks to months) effectiveness.

\section{Chlorination}

Shock treatment at 20 to $500 \mathrm{ppm}$ provides only temporary results and is corrosive to pipes and produces potentially carcinogenic DBP's. Continuous chlorination at 1-2 ppm is not effective. Chlorine is significantly less effective in hot water systems which are the main foci of Legionella proliferation.

\section{Ultraviolet (UV) Radiation}

Provides effective point of source disinfection only, but no residual and thus not effective for systems already contaminated. High energy costs and requires very clean water with low turbidity and suspended solids.

\section{Ozonation}

Similar limitations as UV.

\section{Copper-Silver ionization}

Effective treatment with residual, but high initial equipment cost. Hard water and $\mathrm{pH}$ higher than 8 may limit effectiveness and may increase costs. Health restrictions on copper and/or silver in drinking water may limit use and there are problems of corrosiveness.

\section{Chlorine Dioxide}

Effective treatment, however, it must be generated onsite and commercially available treatment plant costs for small scale systems such as hospitals and hotels are high. This method, while effective involves possible health risks and has been disallowed in some countries.

\section{Mono-Chloramine}

More effective in municipal systems than chlorine and fewer DBP's but like chlorine has reduced efficacy at high temperature of hot water systems which are the major foci for Legionella.

\section{The Acceptability of the Disinfectant Formulation for Treatment of Drinking Water}

The active ingredients of the commercial disinfectant formulation under study are non-toxic $\mathrm{H}_{2} \mathrm{O}_{2}$ and silver. $\mathrm{H}_{2} \mathrm{O}_{2}$ has been approved for drinking water disinfection at the concentration required for this anti-Legionella treatment in Europe under "European Standard- EN 902-1999 - Chemicals used for treatment of water intended for human consumption-hydrogen peroxide". The use of silver at the concentration required for drinking water disinfection has been approved by the WHO, the EU and the United States Environmental
Protection Agency. The commercial formulation has been specifically approved for drinking water disinfection by the USEPA under FIFRA, by the Drinking Water Inspectorate (DWI) in the United Kingdom and the by health authorities in Australia. The product has also been approved for Legionella control under the regime used in this study by the Israel Ministry of Health.

\section{Conclusion}

From the results of this full scale 24 month field test in a 50 bed hospital ward, it can be concluded that 
the procedure reported upon here, based on the use of a stabilized formulation of hydrogen peroxide containing a minute amount of oligodynamic silver is a promising and economical option for the effective long term control of Legionella bacteria in closed loop hot water systems of hospitals, hotels and similar institutions. The non-toxic, taste free and heat stable, bactericidal/bactiostatic formulation studied has the unique qualities of providing an effective long lasting disinfection residual in piping systems and an increase of disinfection power in hot water systems making it particularly effective in the control of Legionella in such institutions.

\section{Acknowledgements}

This study was carried out under the sponsorship of Swissteril Water Purification Ltd, Haifa, Israel, who supplied the disinfectant-Steril, used in this study and in cooperation with the appropriate authorities and staff of the Rambam hospital and the Ministry of Health, Public Health Laboratory, Haifa. Mr. Alon Lehrer and Mr. Nimrod Ben-Yehuda of the Swissteril management planned, designed, installed and operated the special disinfection feed, and control system. Additional financing for certain phases of the study were provided by the US Environmental Protection Agency-EPA and the Research Division of the European Union.

\section{References}

1. Association of Water Technologies (AWT). LEGIONELLA 2003: An Update and Statement. The Association of Water Technologies, Rockville MD 2003. www.awt.org

2. Yarom R, Sheinman R. Contamination of Legionella pneumophila in hot water distribution systems in hospitals across Israel. In: Proc $7^{\text {th }}$ Int Conf of Israel Society of Ecology and Environmental Quality Sciences- ISEEQS. Tel Aviv 1999.

3. Oren I, Zukerman T, Avivi I, Finkelstein R, Yigla M, Rowe JM. Nosocomial outbreak of Legionella pneumophila serogroup 3 pneumonia in a new bone marrow transplant unit: evaluation, treatment and control. Bone Marrow Transplantation 2002; 30: $175-179$.

4. Shuval H, Fattal B, Bercovier H. Legionnaires disease and the water environment in Israel. Wat Sci Tech 1989; 20: 11-12.

5. Edelstein, P.H. (2000) Legionella. In: Lannette EH, Balows A, Hausler WJJ, Shadomy HJ, Eds. Manuel of Clinical Microbiology, $4^{\text {th }}$ edn. Washington, DC: American Society of Microbiology 2002; 373-381.

6. Barbaree JM, Morill WE, Fields BS. Detection and recovery of legionella in water. Toxicity Assessment 1988; 3: 479-490.

7. Shuval H. Stabilized formulation of hydrogen peroxide with silver: a secondary disinfectant. In: Cotruvio JA, Craun GF, Hearne N, Eds. Safe Drinking Water in Small Systems: Technology, Operation and Economics. Lewis Publishers, New York 1999.

8. Pedahzur R, Shuval HI, Ulitzur S. Silver and hydrogen peroxide as potential drinking water disinfectants: Their bactericidal effects and possible modes of action. Wat Sci and Tech 1997; 35(11-12): 87.

9. Pedahzur R, Katzenelson D, Barnea N, et al. The efficacy of long-lasting residual drinking water disinfectants based on hydrogen peroxide and silver. Wat Sci Tech 2000; 42: 293 298.

10. Maki D. New York Times, December 20th 2005. 